Short Paper

\title{
Separation of Saturated Glyceryl Ethers from Lipid Unsaponifiable Matter by a Combination of Hydrogenation and Recrystallization
}

\author{
Kenji Hayashi \\ Faculty of Fisheries, Hokkaido University, Hakodate, Hokkaido 041-8611, Japan \\ (Received March 13, 1997)
}

Key words: recrystallization, hydrogenation, starfish, lipid, unsaponifiable matter, glyceryl ether, batyl alcohol

The pyloric cecal and / or ovarian lipids of starfish Asterias rubens, ${ }^{1)}$ A. lincki ${ }^{2)}$ Ctenodiscus crispatus, ${ }^{2)}$ Pteraster militaris, ${ }^{2)}$ Solaster paxillatus, ${ }^{3)}$ and $A$. amurensi ${ }^{3)}$ contain significant amounts of glyceryl ethers present in the form of diacyl glyceryl ethers. These starfish species are a good source of glyceryl ethers. Glyceryl ethers of marine origin have proven useful as natural surface-active or softening agents in cosmetics and ointments. In the previous report, we demonstrated the separation of highly-purified glyceryl ethers rich in saturates from unsaponifiable matter of the gonatid squid liver lipids by the use of a simple and lowcost recrystallization method. ${ }^{4)}$ Also, it was found that glyceryl ethers from the tissue lipids of $S$. paxillatus and $A$. amurensis had saturates with $18: 0$ and 16:0 alcohols and monoenes with 20:1 and 18:1 ones. ${ }^{3)}$ The present investigation was undertaken to find a convenient method for separation of saturated glyceryl ethers in a reasonable yield from unsaponifiable matter of the starfish tissue lipids.

An aliquot of each of the pyloric cecal and ovarian lipids obtained from $S$. paxillatus and $A$. amurensis, ${ }^{3)}$ was subjected to hydrolysis in alcoholic KOH by boiling under reflux for $1 \mathrm{~h}$. The unsaponifiable matter was extracted from the saponified mixture with diethyl ether. The unsaponifiable matter was then hydrogenated in a methanol solution with $5 \%$ palladium catalyst (Nakarai Chemicals), and hydrogen was bubbled at atmospheric pressure and at room temperature for $1 \mathrm{~h}$. Upon recrystallization at $2^{\circ} \mathrm{C}$ from a $n$-hexane solution of the hydrogenated unsaponifiable matter, the solid fraction was separated as white crystal grains. The methods used for qualitative and quantitative determination of constituent lipids by thin-layer chromatography and an Iatroscan $\mathrm{TH}-10$ flame ionization detector (Iatron Lab. Inc.), preparation of isopropylidene derivatives of glyceryl ethers, and determination of the above compounds by gas-liquid chromatography were performed as described in a previous report. ${ }^{5)}$

The pyloric cecal and ovarian lipids of the starfish studied contained $19.5 \%$ and $83.1 \%$ of diacyl glyceryl ethers for $S$. paxillatus and $19.5 \%$ and $13.6 \%$ for $A$. amurensis, respectively. The level and class composition of unsaponifiable matter in the tissue lipids from these starfish species are listed in Table 1. Also, Table 1 shows the yield and composition of the solid fraction separated by the first recrystallization from the hydrogenated unsaponifiable matter.
The pyloric cecal and ovarian lipids of the examined starfish contained considerable amounts of unsaponifiable matter, accounting for $13.4 \%$ and $32.2 \%$ for $S$. paxillatus and $11.9 \%$ and $11.7 \%$ for $A$. amurensis, respectively. On the other hand, the hydrogenated unsaponifiable matter of the above tissue lipids consisted of $61.0 \%$ and $85.7 \%$ of glyceryl ethers and $29.1 \%$ and $10.2 \%$ of sterols for S. paxillatus and of $74.4 \%$ and $36.6 \%$ of the former compounds and $13.5 \%$ and $27.8 \%$ of the latter ones for $A$. amurensis, respectively. Of both the starfish species, the tissue lipid un-

Table 1. Lipid component and glyceryl ether composition of hydrogenated unsaponifiable matter of starfish tissue lipids and their solid fractions separated by recrystallization

\begin{tabular}{|c|c|c|c|c|}
\hline & \multicolumn{2}{|c|}{ S. paxillatus } & \multicolumn{2}{|c|}{ A. amurensis } \\
\hline & $\begin{array}{l}\text { Pyloric } \\
\text { cecum }\end{array}$ & Ovary & $\begin{array}{l}\text { Pyloric } \\
\text { cecum }\end{array}$ & Ovary \\
\hline Unsaponifiable matter $\%{ }^{* 1}$ & 13.4 & 32.2 & 11.9 & 11.7 \\
\hline \multicolumn{5}{|l|}{ Component $\%{ }^{* 2}$} \\
\hline Glyceryl ethers & 61.0 & 85.7 & 74.4 & 36.6 \\
\hline Sterols & 29.1 & 10.2 & 13.5 & 27.8 \\
\hline Free fatty acids & 4.5 & 2.4 & 4.2 & 3.3 \\
\hline Polar compounds & 5.4 & 1.7 & 7.9 & 32.3 \\
\hline Solid fraction $\% * 3$ & 53.0 & 83.5 & 53.3 & 36.0 \\
\hline \multicolumn{5}{|l|}{ Component $\% *_{4}$} \\
\hline Glyceryl ethers & 96.2 & 98.6 & 95.2 & 90.1 \\
\hline Polar compounds & 3.8 & 1.4 & 4.8 & 9.9 \\
\hline \multicolumn{5}{|c|}{ Glyceryl ether component \% } \\
\hline $15: 0^{* 5}$ & 0.6 & 0.4 & 1.1 & 1.1 \\
\hline $16: 0$ & 7.4 & 20.5 & 10.2 & 10.4 \\
\hline $17: 0$ & 4.1 & 3.8 & 6.0 & 6.0 \\
\hline $18: 0$ & 60.5 & 37.8 & 67.9 & 64.8 \\
\hline $19: 0$ & 4.5 & 3.1 & 2.8 & 2.9 \\
\hline $20: 0$ & 18.4 & 33.0 & 5.3 & 6.8 \\
\hline Br 16:0 & 0.3 & $\operatorname{tr}$ & 1.7 & 2.2 \\
\hline Вг17:0 & 0.8 & 0.3 & 1.8 & 2.5 \\
\hline $\mathrm{Br} 19: 0$ & 2.5 & 0.6 & 1.5 & 1.5 \\
\hline Others ${ }^{*_{6}}$ & 0.9 & 0.5 & 1.7 & 1.8 \\
\hline
\end{tabular}

*1\% to total lipids.

$*_{2} \%$ to hydrogenated unsaponifiable matter.

*3 Solid fraction was separated from hydrogenated unsaponifiable matter by recrystallization.

$*_{4} \%$ to solid fraction.

*s Indicated by chain length and double bond of alkyl moiety.

*6 Consisted of 14:0, Br15:0, and Br18:0 alcohols. Br: Branched, tr: Trace (less than 0.05\%). 
saponifiable matter before hydrogenation contained minute amounts of alkenyl glyceryl ethers (1.9-5.9\%), which were converted to saturated glyceryl ethers after hydrogenation. Small amounts of free fatty acids contaminated were also detected in the unsaponifiable matter before and after hydrogenation.

As shown in Table 1, the solid fractions for the pyloric ceca and ovaries of $S$. paxillatus yielded $53.0 \%$ and $83.5 \%$ of the hydrogenated unsaponifiable matter and consisted of $96.2 \%$ and $98.6 \%$ of glyceryl ethers, respectively. Also, for the pyloric ceca and ovaries of $A$. amurensis, the solid fractions yielded $53.3 \%$ and $36.0 \%$ of the hydrogenated unsaponifiable matter and cosisted of $95.2 \%$ and $90.1 \%$ of glyceryl ethers, respectively. These solid fractions of crystalline grains were free from saturated sterols and/or saturated free fatty acids. Thus, the yields of glyceryl ethers in the solid fractions to the amounts of total glyceryl ethers in the hydrogenated unsaponifiable matter were 83.6$97.4 \%$ for $S$. paxillatus and $68.2-88.6 \%$ for $A$. amurensis.

The glyceryl ethers in the separated solid fractions contained only saturates with 18:0 (batyl alcohol: $37.8-60.5 \%$ for S. paxillatus and 64.8-67.9\% for $A$. amurensis), 20:0 (18.4-33.0\%; 5.3-6.8\%), and 16:0 (chimyl alcohol: 7.4$20.5 \%$; 10.2-10.4\%) alcohols as major constituents. Between the examined tissues of $\boldsymbol{A}$. amurensis, the glyceryl ethers separated from the hydrogenated unsaponifiable matter were similar in composition; the most predominant component was 18:0 alcohol followed by 16:0 alcohol. On the other hand, between the examined tissues of $S$. paxillatus the separated glyceryl ethers were somewhat different in composition. The predominant components were 18:0 and 20:0 alcohols for pyloric ceca and 18:0, 20:0, and 16:0 ones for ovaries, respectively. The percentages of 20:0 alcohol in $S$. paxillatus were higher than those in $A$. amurensis. These solid fractions also consisted of considerable amounts of odd numbered glyceryl ethers (7.3-10.0\%) and branched chain compounds (1.1-7.7\%). (7.3-10.0\%).

Finally, 0.6-2.1 g of saturated glyceryl ethers (purity: 96-99\%) were separated from $100 \mathrm{~g}$ of the wet tissues of $S$. paxillatus and $0.1-0.6 \mathrm{~g}$ of saturated ones (90-95\%) were separated from those of $A$. amurensis. The combination of hydrogenation and recrystallization is applicable to large-scale separation of highly-purified saturated glyceryl ethers from marine resources.

\section{References}

1) W. V. Allen: J. Mar. Biol. Ass. U. K., 48, 521-533 (1968).

2) I.-B. Falk-Petersen and J. R. Sargent: Mar. Biol., 69, 291-298 (1982).

3) K. Hayashi and H. Kishimura: Fisheries Sci., 63, 945-949 (1997).

4) K. Hayashi: Nippon Suisan Gakkaishi, 52, 1475 (1986).

5) K. Hayashi: Nippon Suisan Gakkaishi, 55, 1383-1387 (1989). 